\title{
Using Circular Open Field Thigmotaxis to Test Fermented Plant Extracts as Rat Repellents
}

\author{
${ }^{1}$ Kan Khoomsab, ${ }^{2}$ Thanthiya Janseeda and ${ }^{2}$ Panthip Saicomton \\ ${ }^{I}$ Education Science Program, Faculty of Science and Technology, \\ Phetchabun Rajabhat University, Phetchabun, Thailand \\ ${ }^{2}$ Biology Program, Faculty of Science and Technology, \\ Phetchabun Rajabhat University, Phetchabun, Thailand
}

Article history

Received: 08-02-2019

Revised: 04-04-2019

Accepted: 23-04-2019

Corresponding Author:

Kan Khoomsab

Education Science Program,

Faculty of Science and

Technology, Phetchabun

Rajabhat University,

Phetchabun, Thailand

Email: topkan13@hotmail.com

\begin{abstract}
We investigated the efficacy of five fermented plant extracts (kaffir lime, noni, garlic, chili and mint) as rat repellents, using circular open field thigmotaxis. Plants were fermented for 1,3 and 5 days. Rats (Rattus rattus) were exposed to fermented plant extracts placed in the core zone (central area) of a circular open field. Rat behaviors in the field were observed for one hour and movements within the outer, middle and core zones of the field were recorded. Rats showed anxiety and aversion to the circular open field's core zone. The average time (in minutes) that rats spent in the three zones was compared using a one-way ANOVA. Rats showed the highest aversion responses to noni and kaffir lime extracts. Calculation of thigmotactic ratios revealed that fermented noni and kaffir lime had higher scores than any of the other plants. Our results show that noni and kaffir lime could be used in rat repellent products, which would be low cost and environmental friendly.
\end{abstract}

Keywords: Fermented Plant Extracts, Rat Repellent, Circular Open Field

\section{Introduction}

Rats can cause significant damage to agricultural products, dwellings and structures. Moreover, rats carry germs and diseases, such as the plague, that affect human health. Patients suffering from the plague may experience sepsis, fever, neurosis, lymphadenopathy and bleeding related to inflammation; without proper treatment, death can occur. Leptospirosis, which occurs most frequently during the rainy season and scrub typhus are also transmitted by rats (Tangkanakul et al., 2005; Singla et al., 2008; Hinjoy, 2014; Singla et al., 2016). Rodenticides are widely used in Thailand as they are convenient and provide rapid and certain results. However, when rats are killed, the chemicals used in rodenticides disperse and persist in the environment and can affect human and pet health (Trakulsrichai et al., 2017; Vyas, 2017). Accordingly, the chemicals mainly affect the cardiovascular, respiratory, Gastrointestinal (GI), hepatobiliary and hematologic systems and causes electrolyte and metabolic abnormalities (Trakulsrichai et al., 2017).

Allelopathy is the biochemical phenomenon whereby secondary metabolites (allelochemicals) released by plants influence the growth, development, or behavior of other organisms and it is often applied in agriculture. The smell of some plants can have a repellent effect on animals, causing them to avoid the source of the smell and such chemicals could be used to produce rat repellents (Nielsen et al., 2015). Plant products are safer for the environment than many rodenticides as they are non-toxic to ecosystems, agricultural products, humans and pets. Using plants that are easily found in local areas as repellents against pest animals can also reduce expenses.

Singla et al. (2014) found that eucalyptus oil (5\% and $10 \%$ ) repelled both male and female rats (Rattus rattus). Singla and Kaur (2014) used citronella oil, applied as a paint in laboratory pens and found that food consumption from the treated side of the pen was significantly lower $(p<0.05)$ compared to the untreated side, indicating a significant repellent effect of the oil. Kalandakanond-Thongsong et al. (2011) used bergamot oil to coat cardboard paper and found that this significantly reduced biting and chewing by rats.

Circular open field tests were first introduced by Hall in 1934 as a tool for measuring rats' emotional condition (Michael and Michael, 2015). A circular open field arena is an important apparatus for studying the activities of 
experimental animals in behavioral neuroscience. Animals are exposed to a stimulus and their behavior is recorded, including their activity in the area close to the stimulus, avoidance behaviors and signs of anxiety (Beatrice et al., 1994; Sestakova et al., 2013). These tests are now one of the most widely used tools in animal psychology studies (Seibenhener and Wooten, 2015). Behaviors such as thigmotaxis (staying close to the walls of the field (and defecation are indicators of anxiety or fear, while time spent in the center of the field and high locomotor activity indicate exploratory behavior. Rats with high levels of anxiety spend less time in the center of the field and have low levels of locomotion (Hines and Minton, 2012).

This study used circular open field thigmotaxis to test the efficacy of five plant extracts in repelling rats.

\section{Materials and Methods}

\section{Preparation of Plant Samples}

Five plants available in Mueang District, Phetchabun Province, Thailand, were used in this study: Kaffir lime fruits, chili fruits, mint leaves, garlic bulbs and noni fruits. Fresh plant samples were macerated in ethyl alcohol for 1, 3, or 5 days. Samples were then fermented further at 1:1 plant: solvent in a closed container. The fermented plants were then strained and the liquid was retained for the experiments.

\section{Use of a Circular Open Field to Test Responses to Fermented Plant Extracts}

A circular open field arena was used to test rats' responses to plant extracts. The stimulus in this experiment was fermented plant extract-soaked cotton balls that were placed in the core zone of the circular open field (Fig. 1).

Cotton balls were soaked in the fermented plant extract for one day and were then squeezed until almost dry and rolled in tissue paper. The tissue paper was slightly sprayed with the fermented plant extract again and then placed in the core zone of the apparatus. Three male and three female white rats (Wistar rat) per treatment weighing $180 \mathrm{~g}$ was placed in the test apparatus to monitor movement behavior (locomotor activity). After a one-hour adaptation period, tests were conducted using one-, three- and five-day fermented plant extracts. Test treatments were repeated three times. The treatments were (1) fresh water (the control group); (2) fermented mint extract; (3) fermented noni extract; (4) fermented kaffir lime extract; (5) fermented chili extract; and (6) fermented garlic extract.

\section{Data Analysis}

Rat behavior was observed for $24 \mathrm{~h}$ using a video recorder. The amount of time that each rat spent in each zone, (core, middle and outer) was recorded to the nearest minute. A one-way ANOVA was used to compare the average time (minutes) spent in each zone with each treatment. Duncan's new Multiple Range Test (DMRT) was used to assess the significance level for differences between means. The thigmotactic ratio was calculated as:

Thigmotactic ratio $=\frac{\text { Outer zone time }}{(\text { Middle zone time }+ \text { Core zone time })}$

The ratio is an index of anxiety or aversive behavior in response to a stimulus.

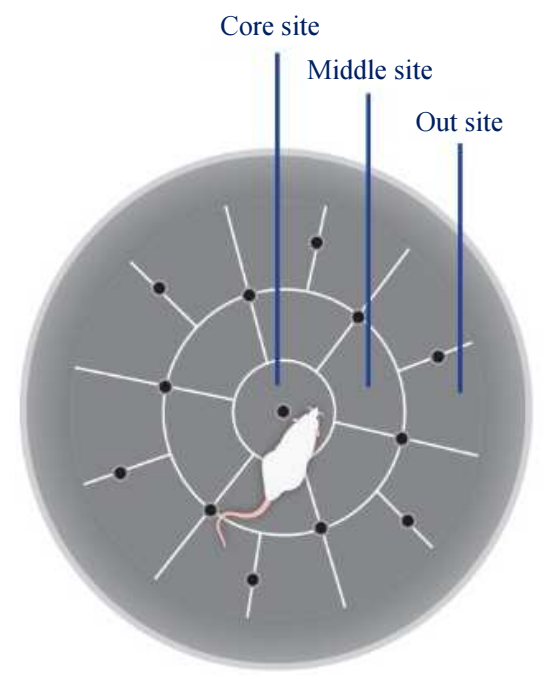

Fig. 1: Circular open field 


\section{Results and Discussion}

In tests with extracts fermented for one day, rats spent the least amount of time in the core zone when exposed to noni and kaffir lime extracts (Table 1), which was significantly less than the average time for other treatments $(\mathrm{p}<0.05)$. Rats in the control group showed the highest levels of activity in the core zone $(p<0.05)$ (Table 1), while rats in the treatment groups spent most of the time in the outer zone or seeking and climbing. Mint extract also affected rat behavior and the rats spent significantly more time in the outer zone $(\mathrm{p}<0.05)$.

Table 2 shows that the results with extracts fermented for three days were consistent with those for extracts fermented for one day. The fermented noni extract repelled the rats most, followed by the kaffir lime, mint, garlic and chili extract. Rats exposed to kaffir lime extract did not visit the core zone, indicating high avoidance behavior.

The study results for extracts fermented for five days were also consistent with those of one-day and three-day fermented extracts (Table 3). Experimental rats did not enter the core zone when exposed to five-day fermented noni extract.

The thigmotactic ratios showed that the fermented noni and kaffir lime extracts had higher scores than other fermented plant extracts (Fig. 2). Therefore, fermented noni and kaffir lime extracts showed greater efficacy as rat repellents than other fermented plant extracts.

Table 1: Time (mean \pm SD) of rat activity in different zones of a circular open field when exposed to five plant extracts fermented for one day

\begin{tabular}{|c|c|c|c|}
\hline \multirow[b]{2}{*}{ Treatment } & \multicolumn{3}{|l|}{ Time $(\min )$} \\
\hline & Outer zone & Middle zone & Core zone \\
\hline Water (Control) & $8.50 \pm 2.50^{\mathrm{b}, \mathrm{E}}$ & $9.50 \pm 3.14^{\mathrm{b}, \mathrm{B}}$ & $42.00 \pm 3.95^{\mathrm{a}, \mathrm{A}}$ \\
\hline Kitchen mint & $38.67 \pm 8.09^{\mathrm{a} . \mathrm{C}}$ & $12.28 \pm 5.32^{\mathrm{b}, \mathrm{B}}$ & $9.19 \pm 8.41^{\mathrm{b}, \mathrm{C}}$ \\
\hline Noni & $58.37 \pm 1.23^{\mathrm{a}, \mathrm{A}}$ & $1.46 \pm 1.17^{\mathrm{b}, \mathrm{C}}$ & $0.16 \pm 0.26^{\mathrm{b}, \mathrm{D}}$ \\
\hline Kaffir lime & $53.58 \pm 6.14^{\mathrm{a}, \mathrm{B}}$ & $5.60 \pm 5.81^{\mathrm{b}, \mathrm{B}}$ & $0.60 \pm 1.34^{\mathrm{b}, \mathrm{D}}$ \\
\hline Chili & $21.63 \pm 10.55^{\mathrm{a}, \mathrm{D}}$ & $22.09 \pm 11.03^{\mathrm{a}, \mathrm{A}}$ & $16.27 \pm 5.17^{\mathrm{a}, \mathrm{B}}$ \\
\hline Garlic & $26.76 \pm 7.39^{\mathrm{aD}}$ & $20.71 \pm 7.66^{\mathrm{b}, \mathrm{A}}$ & $12.52 \pm 5.05^{\mathrm{c}, \mathrm{B}}$ \\
\hline
\end{tabular}

Different capital letters indicate significant differences between treatments within zones $(\mathrm{p}<0.05)$

Different lowercase letters indicate significant differences between zones within treatments $(\mathrm{p}<0.05)$

Table 2: Time (mean \pm SD) of rat activity in different zones of a circular open field when exposed to five plant extracts fermented for three days

\begin{tabular}{|c|c|c|c|}
\hline \multirow[b]{2}{*}{ Treatment } & \multicolumn{3}{|l|}{ Time (minute) } \\
\hline & Outer zone & Middle zone & Core zone \\
\hline Water (Control) & $8.50 \pm 2.31^{\mathrm{b}, \mathrm{C}}$ & $9.50 \pm 3.42^{\mathrm{b}, \mathrm{B}}$ & $42.00 \pm 12.93^{\mathrm{a}, \mathrm{A}}$ \\
\hline Kitchen mint & $31.75 \pm 9.14^{\mathrm{a}, \mathrm{B}}$ & $13.97 \pm 9.52^{\mathrm{b}, \mathrm{B}}$ & $14.27 \pm 7.51^{\mathrm{b}, \mathrm{BC}}$ \\
\hline Noni & $53.74 \pm 3.67^{\mathrm{a}, \mathrm{A}}$ & $5.47 \pm 3.31^{\mathrm{b}, \mathrm{C}}$ & $0.58 \pm 0.81^{\mathrm{c}, \mathrm{D}}$ \\
\hline Kaffir lime & $51.21 \pm 8.11^{\mathrm{a}, \mathrm{A}}$ & $8.58 \pm 8.36^{\mathrm{b}, \mathrm{B}}$ & - \\
\hline Chili & $24.00 \pm 10.83^{\mathrm{a}, \mathrm{B}}$ & $18.20 \pm 6.87^{\mathrm{a}, \mathrm{B}}$ & $17.80 \pm 8.81^{\mathrm{a}, \mathrm{B}}$ \\
\hline Garlic & $29.87 \pm 16.95^{\mathrm{a}, \mathrm{B}}$ & $22.46 \pm 18.35^{\mathrm{ab}, \mathrm{A}}$ & $7.66 \pm 8.56^{b, C D}$ \\
\hline
\end{tabular}

Different capital letters indicate significant differences between treatments within zones $(\mathrm{p}<0.05)$

Different lowercase letters indicate significant differences between zones within treatments $(\mathrm{p}<0.05)$

Table 3: Time (mean $\pm \mathrm{SD}$ ) of rat activity in different zones of a circular open field when exposed to five plant extracts fermented for five days

\begin{tabular}{|c|c|c|c|}
\hline \multirow[b]{2}{*}{ Treatment } & \multicolumn{3}{|l|}{ Time (min) } \\
\hline & Outer zone & Middle zone & Core zone \\
\hline Water (Control) & $8.50 \pm 2.58^{\mathrm{b}, \mathrm{D}}$ & $9.50 \pm 7.92^{b, \mathrm{~B}}$ & $42.00 \pm 8.41^{\mathrm{a}, \mathrm{A}}$ \\
\hline Kitchen mint & $32.00 \pm 9.41^{\mathrm{a}, \mathrm{B}}$ & $20.11 \pm 9.63^{\mathrm{b}, \mathrm{A}}$ & $7.87 \pm 4.90^{\mathrm{c}, \mathrm{C}}$ \\
\hline Noni & $58.90 \pm 12.78^{\mathrm{a}, \mathrm{A}}$ & $1.10 \pm 4.78^{\mathrm{b}, \mathrm{C}}$ & - \\
\hline Kaffir lime & $54.40 \pm 2.60^{\mathrm{a}, \mathrm{A}}$ & $4.40 \pm 2.60^{\mathrm{b}, \mathrm{BC}}$ & $1.20 \pm 8.78^{\mathrm{b}, \mathrm{C}}$ \\
\hline Chili & $22.00 \pm 5.67^{\mathrm{a}, \mathrm{C}}$ & $17.40 \pm 7.40^{\mathrm{a}, \mathrm{A}}$ & $21.00 \pm 5.52^{\mathrm{a}, \mathrm{B}}$ \\
\hline Garlic & $29.89 \pm 10.86^{\mathrm{a}, \mathrm{BC}}$ & $22.84 \pm 6.66^{\mathrm{a}, \mathrm{A}}$ & $7.26 \pm 13.43^{b, C}$ \\
\hline
\end{tabular}

Different capital letters indicate significant differences between treatments within zones $(p<0.05)$

Different lowercase letters indicate significant differences between zones within treatments $(\mathrm{p}<0.05)$ 


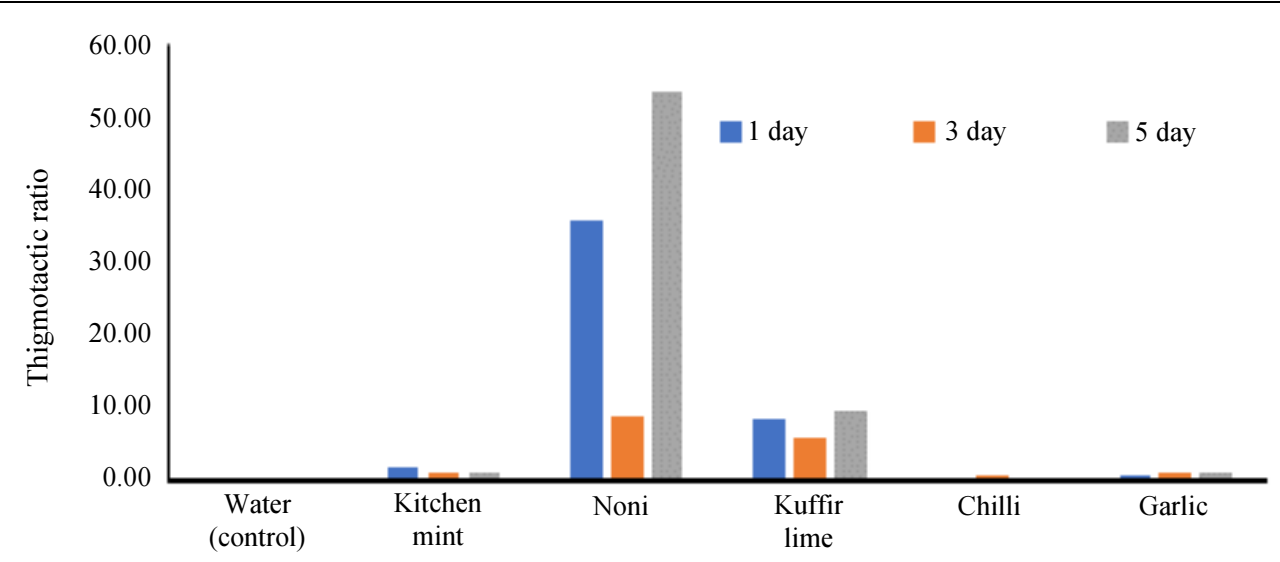

Fig. 2: Mean thigmotactic ratios for rats exposed to fermented plant extracts

Our results showed that rats showed aversive behavior to the smell of fermented plant extracts. Generally, rats show biting behavior but the rats tested avoided all five fermented plant extracts. Rats showed the greatest aversion to noni and kaffir lime extracts, followed by mint, garlic and chili. Rats stayed in the outer zone longest when they were exposed to noni. We also noted that the rats appeared to experience itchiness over the whole body. The fermented plant extracts were acrid and emitted butyric acid, a weak acid produced by Clostridium bacteria during fermentation in the absence of oxygen. Butyric acid (butanoic acid) is a carboxylic acid found in butter and other dairy products and is the source of the noxious smell of human vomit. In previous studies, it induced avoidance behavior in laboratory rats and had a deterrent effect on wild Norway rats when mixed into food (Barnett and Spencer, 1953; Wallace and Rosen, 2000).

Maceration is used to extract essential substances from plants by soaking the plant material in a stoppered container with a solvent at room temperature for a period of 12-24 $\mathrm{h}$ or more, but not longer than two days (although for some plants the period can be seven days). The advantage of this method is that the substance is not exposed to heat; however, a large amount of solvent is required. Decoction is a method of extraction involving boiling herbal or plant material, which may include stems, roots, bark and rhizomes (Azwanida, 2015). However, extraction from the various plant parts may require different solvents and methods, depending on what kind of essential substances are required and what kind of properties the substances have. For example, polar substances (water-soluble substances such as organic acid in tamarind), semi-polar substances (alcohol solutions, such as tannins in mangosteen peel) and nonpolar substances (water-insoluble substances, such as essential oils) can be extracted by using hexane or by steam or water distillation.
Kalandakanond-Thongsong et al. (2011) tested essential oils as rat repellents and found that geranium and kaffir lime essential oils showed potential. These extracts can activate the brains of vertebrates, especially the olfactory system (Witt et al., 2009) and smells can stimulate aversive behaviors (Doty, 1986). Singla et al. (2014) tested rat responses to eucalyptus oil extract at $5 \%$ concentration and found that rats avoided the areas with the repellent and urinated and defecated a lot. Our results are consistent with this study.

Open field tests are one of the most widely used measures of behavior in animal psychology. The open field test provides simultaneous measures of locomotion, exploration and anxiety (Hines and Minton, 2012; Vidal, 2014). The number of line crosses and frequency of rearing are usually used as measures of locomotor activity but are also measures of exploration and anxiety. A high frequency of these behaviors indicates increased locomotion and exploration and lower levels of anxiety. The number of core zone entries and the duration of time spent in the core zone are measures of exploratory behavior and anxiety. A high frequency of these behaviors indicates high exploratory behavior and low levels of anxiety. Thigmotaxis is the movement of an organism either towards or away from the stimulus of physical contact. Such movements are interpreted as signs of fear or aversive behavior in response to a stimulus (Beatrice et al., 1994; Lamprea et al., 2008). Our results revealed that the rats tried to stay close to the wall of the circular open field. Such behavior is called thigmotactic or wall-seeking behavior. Experimental rats tried to climb the wall to escape from the stimulus and showed anxiety or fear, indicated by frequent urination and defecation (Bourin et al., 2007).

Allelopathy is the biochemical phenomenon whereby secondary metabolites (allelochemicals) released by plants influence the growth, development or behavior of plants, microorganisms and animals. The substances may be released from plants by evaporation, washing from 
root, leaf, flower and fruits, or extraction from the plant material (Nath et al., 2016). When animals are exposed to these substances, their physiology and behavior may be controlled by the hypothalamic-pituitary-adrenal axis, the system that controls reactions to fear and stress (File, 2001). This stress theory was founded by Hans Selye, a psychological expert (Steimer, 2011). Animal physiology and behavior research has to refer to theories for trying to describe mechanism, characteristics, gestures, action that can be seen from naked eyes and other mechanisms that cannot be observed with naked eyes such as the function of nervous and hormone systems that have effect on animal behaviors. The techniques used here can be applied to other studies investigating potential products for repelling pest animals.

\section{Conclusion}

Our results showed that rats avoid fermented noni and kaffir lime extracts and these can be used as rat repellent. The development and use of locally available plant products with repellent activity is thus an alternative environmental friendly strategy for rodent control. The use of the circular open field test to observe exploratory behavior and general activity in rodents was validated.

\section{Acknowledgment}

We thank our University for supporting our work.

\section{Authors Contributions}

Kan Khoomsab: Designed experiment, made circular open field, analyzed data and statistics, writing manuscript, publication process.

Thanthiya Janseeda: Prepared plant sample instruments. Records time and data for experiment.

Panthip Saicomton: Prepared animals and cared them.

\section{Ethics}

This experiment was carried out under Animals for Scientific Purposes Act B.E.2558 (2015), License for using and producing animals for scientific purposes number U1-020037-2558, Dr. Kan Khoomsab.

\section{References}

Azwanida, N.N., 2015. A review on the extraction methods use in medicinal plants, principle, strength and limitation. Med. Aromatic Plants, 4: 196-196. DOI: $10.4172 / 2167-0412.1000196$

Barnett, S. and M.M. Spencer, 1953. Responses of wild rats to offensive smells and tastes. Brit. J. Anim. Behav., 1: 32-37.

DOI: $10.1016 / \mathrm{S} 0950-5601(53) 80084-5$
Beatrice, S., M. Kvist and R.K. Salander, 1994. Open field thigmotaxis during various phases of the reproductive cycle. Scandinavian J. Psychol., 35: 220-229. DOI: 10.1111/j.1467-9450.1994.tb00946.x

Bourin, M., B. Petit-Demoulière, B.N. Dhonnchadha and M. Hascet, 2007. Animal models of anxiety in mice. Fundamental Clin. Pharmacol., 21: 567-74. DOI: $10.1111 /$ j.1472-8206.2007.00526.x

Doty, R.L., 1986. Odor-guided behavior in mammals. Experentia, 42: 257-271. DOI: $10.1007 / \mathrm{BF} 01942506$

File, S.E., 2001. Factors controlling measures of anxiety and responses to novelty in the mouse. Behav. Brain Res., 125: 151-157. DOI: $10.1016 / \mathrm{S} 0166-4328(01) 00292-3$

Hines, T.J. and B.R. Minton, 2012. Effects of environmental enrichment on rat behavior in the open field test. Proceedings of the National Conference of Undergraduate Research, Mar. 29-31, UNC Asheville, USA.

Hinjoy, S., 2014. Epidemiology of leptospirosis from Thai national disease surveillance system, 20032012. Outbreak Surveillance Invest. Rep., 7: 1-5.

Kalandakanond-Thongsong, S., S. Daendee, B. Thongsong and V. Chavananikul, 2011. Evaluation of cardboard coated with natural substances in combination with ink on rat repellency. Thai J. Vet. Med., 41: 205-211.

Lamprea, M.R., F.P. Cardenas J., Setem and S. Morato, 2008. Thigmotactic responses in an open-field. Brazilian J. Med. Biol. Res., 41: 135-140. PMID: 18297193

Michael, L.S. and C.W. Michael, 2015. Use of the open field maze to measure locomotor and anxiety-like behavior in Mice. J. Vis. Exp. DOI: $10.3791 / 52434$

Nath, S., P. Yumnam and B. Deb, 2016. Allelopathic effect of lemon plant parts on the seedling germination and growth of lettuce and cabbage. Int. J. Plant Biol. Res., 4: 1054-1054.

Nielsen, B.L., O. Rampin, N. Meunier and V. Bombail, 2015. Behavioral responses to odors from other species: Introducing a complementary model of allelochemics involving vertebrates. Frontiers Neurosci., 9: 226-226. DOI: $10.3389 /$ fnins.2015.00226

Seibenhener, M.L. and M.C. Wooten, 2015. Use of the open field maze to measure locomotor and anxiety-like behavior in mice. J. Visualized Exp., 6: e52434-e52434. DOI: 10.3791/52434

Sestakova, N., A. Puzserova, M. Kluknavsky and I. Bernatova, 2013. Determination of motor activity and anxiety-related behaviour in rodents: Methodological aspects and role of nitric oxide. Interdisciplinary Toxicol., 6: 126-135. DOI: $10.2478 /$ intox-2013-0020 
Singla, L.D., N. Singla, V.R. Parshad, P.D. Juyal and N.K. Sood, 2008. Rodents as reservoirs of parasites in India. Integrative Zool., 3: 21-26. DOI: $10.1111 / \mathrm{j} .1749-4877.2008 .00071 . x$

Singla, N., R.K. Thind and A.K. Mahal, 2014. Potential of eucalyptus oil as repellent against house rat, Rattus rattus. Scientific World J., 2014: 249284-249284. DOI: 10.1155/2014/249284

Singla, N. and R. Kaur, 2014. Potential of citronella oil as rodent repellent measured as aversion to food. Applied Biol. Res., 16: 191-198. DOI: $10.5958 / 0974-4517.2014 .00010 . \mathrm{X}$

Singla, N., P. Dhar, L.D. Singla and K. Gupta, 2016. Patho-physiological observations in natural concurrent infections of helminth parasites of zoonotic importance in the wild rodents, Bandicota bengalensis. J. Parasitic Dis., 40: 1435-1442.

Steimer, T., 2011. Animal models of anxiety disorders in rats and mice :some conceptual issues. Dialogues Clin. Neurosci., 13: 495-506. PMID: 22275854

Tangkanakul, W., H.L. Smits, S. Jatanasen and D.A. Ashford, 2005. Leptospirosis: An emerging health problem in Thailand. Southeast Asian J. Tropical Med. Public Health, 36: 281-288. PMID: 15916031
Trakulsrichai, S., N. Kosanyawat, P. Atiksawedparit, C. Sriapha and A. Tongpoo et al., 2017. Clinical characteristics of zinc phosphide poisoning in Thailand. Therapeut. Clin. Risk Manage., 2017: 335-340. DOI: 10.2147/TCRM.S129610

Vidal, J., 2014. Open field modifications needed to measure, in the mouse, exploration-driven ambulation and fear of open space. UB J. Psychol., 44: 7-19.

Vyas, N.B., 2017. Rodenticide incidents of exposure and adverse effects on non-raptor birds. Sci. Total Environ., 609: 68-76.

DOI: $10.1016 /$ j.scitotenv.2017.07.004.

Wallace, K.J. and J.B. Rosen, 2000. Predator odor as an unconditioned fear stimulus in rats: Elicitation of freezing by trimethylthiazoline, a component of fox feces. Behav. Neurosci., 114: 912-922. DOI: 10.1037/0735-7044.114.5.912

Witt, R.M., M.M. Galligan, J.R. Despinoy and R. Segal, 2009. Olfactory behavioral testing in the adult mouse. J. Visualized Exp., 23: 949-949. DOI: $10.3791 / 949$ 